\title{
Franck FREGOSI, Penser l'islam dans la laïcité
}

Paris, Fayard, 2008, 486 p.

\section{Mustapha Naïmi}

\section{(2) OpenEdition}

1 Journals

\section{Édition électronique}

URL : http://journals.openedition.org/assr/21570

DOI : 10.4000 /assr.21570

ISSN : $1777-5825$

Éditeur

Éditions de l'EHESS

\section{Édition imprimée}

Date de publication : 31 décembre 2009

Pagination : 75-342

ISBN : 978-2-7132-2218-4

ISSN : 0335-5985

Référence électronique

Mustapha Naïmi, «Franck fregosı, Penser l'islam dans la laïcité », Archives de sciences sociales des religions [En ligne], 148 | octobre-décembre 2009, document 148-52, mis en ligne le 27 janvier 2010, consulté le 21 septembre 2020. URL : http://journals.openedition.org/assr/21570 ; DOI : https:// doi.org/10.4000/assr.21570

Ce document a été généré automatiquement le 21 septembre 2020.

(c) Archives de sciences sociales des religions 


\title{
Franck FREGOSI, Penser l'islam dans la laïcité
}

Paris, Fayard, 2008, 486 p.

\author{
Mustapha Naïmi
}

\section{RÉFÉRENCE}

Franck fREGosI, Penser l'islam dans la laïcité, Paris, Fayard, 2008, 486 p.

1 Étant à la mode, l'islam est entouré de toute une littérature qui, en France, se nourrit de clichés empreints de paternalisme et alimentés de faits divers mobilisés de façon unilatérale en vue de démontrer que la cohabitation de l'islam et de la République se soldera par l'effondrement progressif de cette dernière et de son modèle d'assimilation, au profil d'un différentialisme aux couleurs de l'islam. L'objectif de l'ouvrage est de démontrer que, par delà les tensions réelles entre l'islam et l'idée de laïcité, dans le contexte français, on assiste à un début d'accommodement. Ce processus est déjà engagé. Les problèmes ponctuels, les incompréhensions qui peuvent parfois survenir en cours de route ne parviennent pas à stopper l'inévitable rencontre entre l'islam en tant que réalité religieuse et la réalité juridique et politique de la laïcité.

2 Pour mener à bien cette réflexion, l'ouvrage part d'une approche dynamique de la communauté musulmane en France. Celle-ci est traversée par des mutations religieuses et sociales qui, d'ores et déjà, témoignent de la pluralité des modes de déclinaison de l'appartenance à l'islam et des degrés différenciés de prise en compte du cadre laïque environnant. En dépit des oppositions théoriques et des tensions pratiques, l'expérience française révèle les nombreuses interactions entre l'identité islamique et le principe de laïcité : elles s'opèrent dans le quotidien des musulmans de France.

Penser l'islam dans la laïcité, c'est aussi poser la question de l'organisation concrète du culte au sein de la société française, historiquement et culturellement non musulmane et profondément sécularisée. La rencontre entre l'islam et la laïcité en France est enfin sous-tendue par de multiples enjeux qui concernent autant le devenir de l'islam que le 
futur de la laïcité. L'islam se trouve ainsi durablement confronté à la particularité d'être une religion minoritaire qui, dans l'exercice public de son culte, rencontre encore quelques difficultés objectives (faible capacité d'autofinancement, maigre patrimoine immobilier, formation des cadres religieux inadaptée au contexte français...) et subjectives (persistance d'une vision dépréciée de l'islam, tendance à la victimisation...) L'islam fait également l'objet d'une multitude de réappropriations, les unes plus identitaires, les autres plus confessionnelles, qui entrent en conflit.

4 La laïcité se trouve ainsi de plus en plus interpellée dans sa capacité opérationnelle à répondre à des demandes cultuelles nouvelles et, plus largement, à réguler une société religieusement plurielle. Elle doit garantir le libre exercice public des cultes sans pour autant faillir à la neutralité religieuse de l'État et au principe de séparation.

Dans ce défi, l'État laïque a un rôle à jouer comme garant de la liberté religieuse et d'une équité en matière d'exercice public des cultes. Il doit, de même, veiller au respect des règles sans non plus se priver d'en adapter la lettre à l'évolution d'une société religieusement plurielle.

Dans le débat sur l'islam et la laïcité, nombreux sont enfin ceux qui prétendent que la solution doit passer par une réforme de fond de la maison islam pour y insuffler plus de liberté, d'autonomie, de rationalité, là où ne règnerait en apparence qu'une loi oppressante, celle du nombre et de la parole intangible de Dieu. Trop souvent, les voix réformatrices ont cru devoir aussi parler en lieu et place de fidèles, réputés trop dévots, et pas assez adultes dans leur façon de vivre leur rapport à la religion. Les musulmans seraient donc inexorablement voués à se laisser guider vers des horizons plus sûrs, par une élite éclairée qui serait seule capable de faire le tri entre l'indispensable et le superflu. À trop vouloir élaguer la forêt de l'islam de ses rites, on risque, à son corps défendant, de faire aussi table rase de sa pluralité au profit d'une vision épurée de la religion, d'une religiosité intellectualisée, c'est-à-dire en somme moins humaine. 